Tarih Kültür ve Sanat Araştırmaları Dergisi

Revue des Recherches en Histoire Culture et Art

مجلة البحوث التاريخية و الثقافية والفنية
Vol. 7, No. 3, September 2018

Copyright (C) Karabuk University

http://kutaksam.karabuk.edu.tr

\title{
DOI: 10.7596/taksad.v7i3.1726
}

Citation: Grigorieva, L. (2018). Poem of P. A. Oyunsky "Tuyarima Kuo Fair-Faced": A Textological Aspect. Journal of History Culture and Art Research, 7(3), 245-252. doi:http://dx.doi.org/10.7596/taksad.v7i3.1726

\section{Poem of P. A. Oyunsky "Tuyarima Kuo Fair-Faced": A Textological Aspect}

\author{
Lyudmila Pavlovna Grigorieva ${ }^{1}$
}

\begin{abstract}
This article focuses on "Tuyarima Kuo Fair-faced" poem's text by Yakut literature classic P. A. Oyunsky (18931939 ) in the aspect of textology and publishing practices. On the basis of comparative analysis of manuscript text and the lifetime edition of 1930 it is established that the text of this edition is the closest to the manuscript, it fully expresses the author's will: there are practically no discrepancies, the author's punctuation is preserved. In this regard, it is concluded that this text can be recognized as the main text of the poem. The study of the manuscript also allowed to reveal new facts reflecting the creative work of P.A. Oyunsky on his text: changing the name of the poem's heroes. Conducted comparative analysis of manuscripts and lifetime edition of 1930 with the 1959th, 1992nd publication showed a significant difference in punctuation, spelling, cases, division into sentences, the deletion of the paragraph, the transfer of sentences, discrepancies in the spelling of character, etc. Hence, first of all, the author's marks in the text of the poem should be restored, because they express the individual style of the writer, also the missing commas in the manuscript and the first edition must be put according to the rules of modern punctuation, which is done in the publication in 1992nd; second of all, the spelling of the writer must be fully restored according to the text of the publication in 1930. In general, the results allow to raise the question of the need for special research in the aspect of textological and publishing practices of all texts of Oyunsky's works with the aim of publishing critically established texts, which would reflect the last will of the writer.
\end{abstract}

Keywords: Yakut literature, Poem, Textology, Main text, Manuscript, Lifetime edition, the author's will, the edition, Comparative analysis.

\footnotetext{
${ }^{1}$ Institute of Languages and Cultures of the Peoples of the North-East of the Russian Federation, North-Eastern Federal University, Yakutsk, Russia. E-mail: grigormila@mail.ru
} 


\section{Introduction}

At present time, the biography of P.A. Oyunsky, his work as a political and social leader of the people, writer and scientist have been studied in detail, presented in serious publications: monographs (Okorokova, 2013; Sidorov, 2016), collections of scientific works and archival materials and documents. At the same time, the texts of P. A. Oyunsky's works have not yet become the subject of a special textological study. Everyone knows what a tragic fate manuscripts and work's texts had suffered before to come to us. Involuntarily there is a question, and whether the last creative will of the author in books which we hold in hands was complied? We have no doubts about the competence and professionalism of the authors of the books published in the second half of the XX and early XXI centuries. In author's opinion, it is time to study the creative heritage of P. A. Oyunsky in the aspect of textology science and publishing practice: the study of texts of works creation history, textological analysis of manuscripts and printed sources, the definition of the main texts of works and, finally, the preparation of scientific publication - the complete works of P.A. Oyunsky.

In this article, we turn to the poem "Tuyarima Kuo Fair-faced", which holds a special place in the creative heritage of P. A. Oyunsky. Our goal is to emphasize the importance of the manuscript and printed texts of the poem in the definition of the main text, to determine the issues of further study of the work's text in the aspect of textology and publishing practice.

As the researchers note, "in relation of Oyunsky to olonkho organically merged researcher's erudition and the heat of poetic inspiration" (Danilov \& Okorokov, 1978, p.23). P.A. Oyunsky was peculiar to feel and be aware of the Yakut heroic epic dramatic nature of the conflict and clearly expressed in it elements of dramatic art. Proof that he paid attention to scenic possibilities inherent in the works of oral folklore, was the creation of "Tuyarima Kuo Fair-faced" poem.

"Tuyarima Kuo Fair-faced" by P. A. Oyunsky was staged in the Yakut theatre in February of 1928. It is known that the poet "approved the first experience of the stage embodiment of olonkho and called this initiative important for the development of the Yakut drama, the Yakut theater. However, the author pointed to serious shortcomings in the production of the play and gave valuable guidance on the performance of a roles" (Semenov, 1980, p.165).

The genre of the work is not defined by the author. In 1930 the writing was published as a book, where it was stated as "üc oonnuulaakh olonkho (norot olonkhotuttan" (lit. "Olonkho in three acts (from the national epic olonkho)") (Oyunsky, 1930). That is why the modern media is often call the poem "Tuyarima Kuo Fairfaced" as olonkho and put on a par with the epic "Nyurgun Bootur the Swift". But we must not forget that this is not olonkho, but an integral and capacious original work created by P. A. Oyunsky on the basis of an acute conflict of the heroic epic (Bilyukina, 1988, p.80). We turned to the manuscript of the poem, which is stored in the national archives of the Republic of Sakha (Yakutia). But a sheet with a title and indication of the genre was not detected. The poem begins with a sheet where is written the dedication (F. P57, op. 1, d. 671). At the end of the manuscript the author clearly indicated the date and place of completion of the poem - July 29, 1930, Yakutsk. In the editions of 1930, 1959 and 1968 retained the author's definition of "Olonkho in three acts (from the national epic olonkho)". In subsequent editions (1975, 1992, 2005) from this definition, it was left that mentioned only in parentheses "(from the national epic olonkho)". As you can see, the modern reader has reached only part of the author's definition. Currently, researchers in the genre of "Tuyarima Kuo Fair-faced" lawfully defined as a dramatic poem (Belyukina, 1988; Chervyachenko, 1979; Grigoriev, 2004, etc.).

In a dramatic poem " Tuyarima Kuo Fair-faced" from the extensive content of the olonkho "Nyurgun Bootur the Swift" P.A. Oyunsky chose the most acute, dramatically significant scenes with the demon's hero Uot Uhutaki, with which takes place tense and dangerous battle for the hero - the fight for beauty Tuyarima 
Kuo. The work is named after the female character, not the hero of the epic "Nyurgun Bootur the Swift". That is the main idea of olonkho - the idea of saving Beauty and Purity from the encroachments of the tribes of the Lower world is transferred to the dramatic poem. The dramatic conflict between two worlds is fully reflected in the image of Tuyarima Kuo.

The compositional structure of the poem "Tuyarima Kuo Fair-faced" is special because it retains the basic compositional techniques of olonkho. The descriptive component required in olonkho is given here in the form of a prologue, which is very important. The functions of the description and narration of the storyteller in the poem are distributed in such purely dramatic elements as remarks and monologues of neutral characters. The analysis of composition structure of the poem and its features, systematics of images and poetics is presented in our other works (Grigorieva, 2004; 2009). The purpose of this article is to study the manuscript and printed sources of the text of the poem "Tuyarima Kuo Fair-faced" in the textology aspect.

\section{Methods}

Modern theoretical foundations of textual criticism, methodologically important for our study are laid in the works of D. S. Likhachev, S. A. Reicer, A. L. Grishunin. Textology as a branch of philology that studies the history of texts based on the study of handwritten sources, comparative critical validation editing, and the history of publishing fiction, receives a special development in the XX century. Study of the manuscript and published works texts can represent a special direction in the study of the literature history. Without it comparative historical and typological comparisons are difficult, which are necessary for coverage of the publishing practice as facts of reference to the classical heritage (Sivtseva-Maksimova \& Nogovitsyn, 2013, p.841). The presented work is carried out within the framework of the methodology of philological analysis in the aspects of comparative historical and literary study of artistic text and sources.

The initial stage of our research can be called informative - identification and study of all text sources (handwritten and printed) of the poem by P. A. Oyunsky "Tuyarima Kuo Fair-faced"; the definition of the sources used for the textological study. At the second stage of the work, a comparative analysis of the manuscript text and the text of the first lifetime edition of 1930 with the texts of the 1959, 1992 editions is carried out.

\section{Questions of definition of the poem main text}

In the textology the work main text is considered to be the last lifetime edition, where the author is directly involved. While the author is alive, he is the only and unquestioned manager of his text: he is able to change or leave unchanged from edition to edition, may go back to an earlier edition, etc. Publisher has to submit to his will. The action of this will is terminated after the death of the author and then "there is a problem of text stabilization - a problem very important in practical and complex in theoretical terms" (Reiser, 1978, p.13). In order to determine the main text, it is necessary to check the printed texts between themselves and with the manuscript.

As noted above, the poem "Tuyarima Kuo Fair-faced" during the author's lifetime was published once in 1930. Verification of a certain volume of the poem's text (prologue and the first action) of the manuscript and the lifetime edition revealed: discrepancies, word omissions, typing errors, changes in the order of words. To confirm this has been compared the manuscript from 29.07.1930 and publishing 1930.

In author's opinion, the text of the lifetime edition is close to the manuscript, identified discrepancies and errors can be easily corrected. Thus, the edition of 1930 will be defined as the main text of the poem "Tuyarima Kuo Fair-faced". 
A study of the manuscript of the poem "Tuyarima Kuo Fair-faced" allowed to identify interesting points, reflecting the author's work on the text. P. A. Oyunsky made amendment, wrote new-lines, etc. We noted the name change of heroes of the poem on Nyurgun Bótur (Nyurgun Bootur) and Ürüng Ôlan (Urung Uolan). Before change in the first action until 7th scene the name of the hero Urung Uolan was Könchœ-böghö Kün Tátyk (Kenche-bogo Kun Tatyk). In the manuscript by the author himself were crossed out 3 lines and wrote the following lines:

\author{
"Visible \\ Above the high fence post, \\ Where triple locks are strong, \\ He flew on a snow-white horse \\ Bogatyr Urung Uolan" (I. 13).
}

It is from this place had started editing the name of a character from Kun Tatyk on Urung Uolan. Further, the author made amendments in 4 places: in 6 phenomenon on 14, 16, 17 pages of the manuscript. With 7 phenomena the name of Urung Uolan already appears in the text of the manuscript. The name of the hero Nyurgun Bootur fixed only once on 10 page of a manuscript, crossed out 4 lines and written a new one. Crossed line, unfortunately, impossible to read.

Thus, it can be concluded that originally P.A. Oyunsky planned to call the characters differently, but in the course of the work changed the main characters names. In the first publication of the poem in 1930, the names of characters are already printed in author's edit. Revealed facts of changing the names of characters reflect the progress of P. A. Oyunsky's work with his text and relate to the text history.

\title{
Textological analysis of printed sources
}

After the rehabilitation of P.A. Oyunsky, was established government Commission to publish the works of writer and in 1957-1962 were published the works in seven volumes. In this edition the second time was published the poem "Tuyarima Kuo Fair-faced" (Oyunsky, 1959). In 1968 came out the single-volume edition of "Selected works", in the Preface it was stated that book are printed on text-based on sevenvolume edition of 1958-1962. This edition was prepared by the daughter of the poet S. P. Oyunskaya; it was written a long biographical article (Oyunsky, 1968, pp.434-437). In 1975 the selected works of the writer were published in two volumes. The poem "Tuyarima Kuo Fair-faced" was printed in the first volume. The publication was prepared by the staff of the Institute of language, literature and history of the Yakut branch of the Siberian department of the USSR Academy of Sciences under the direction of doctor of philology E. I. Korkina, doctor of historical Sciences F. G. Safronov, doctor of Philology G. S. Syromyatnikov. An introductory article was written by Professor A. E. Mordinov (Oyunsky, 1975, pp.5-18). The next edition, where was published the poem "Tuyarima Kuo Fair-faced", is the first volume of selected works in three volumes (1992-1993 a special Commission of scientists of the Institute of language, literature and history, worked on the edition, which included S. P. Oyunskaya. In the introductory article S. P. Oyunskaya noted that the spelling of writer was restored (Oyunsky, 1992, p.11). In this edition for the first time were made comments to the works of writer. In 2005 came out the decree of the President of Sakha (Yakutia) V. A. Shtyrov on the allocation of funds for the publication of collected works of the Sakha literature classics. In this regard, the national book publishing house "Bichik" founded a series of "Classics of Yakut literature". The first edition of this series was the first volume of the collections of selected works by P. A. Oyunsky. Volume included the poem "Tuyarima Kuo Fair-faced" was compiled by M. N. Dyachkovskaya and S. P. Oyunskaya. Here also was preserved the original spelling, as pointed out by the compilers; the 
commentary has been expanded, added new evidence (Oyunsky, 2005). As you can see, on the preparation of publications worked very competent people who were familiar with the principles of publishing works of classical literature. The apparatus of some publications complicated by introductory articles and real comments. In general, we can conclude that the basis for preparation of scientific publications of the collected works of P. A. Oyunsky has been created.

However, in any reprinting of the work, unfortunately, there are new distortions of the text, unwittingly creep any misspellings, new words, omissions etc. It is for these errors that the sequence of the printouts can be established, and, ultimately, the source from which they were made. (Tyurina, 2009, p.106).

We carried out a textological analysis of printed sources of the poem "Tuyarima Kuo Fair-faced" on publications: 1930 (lifetime edition), 1959 (3 Works in 7 vol.) and 1992, where, as argued by the authors, was restored spelling of the writer. A segment of the poem (the prologue and the first action) of about 40 pages was selected for verification. In this case special attention was paid to publications of 1930 and 1959, assuming that if the author made corrections in the text of the poem in 1937, during preparation for printing their works, they can be reflected in the publication of the 1959 edition. The publication of 1992 was of interest in the sense that it was the first time spelling of the writer was restored. In this regard, the subject of comparative analysis were 4 sources: the manuscript and 3 printed text of the poem.

In the manuscript and in the lifetime edition of 1930 there is no indication of the actors. An indication about the characters for the first appeared in the edition of 1959. In the review of publications of 1992 and 2005, nothing about it is noted. Who had decorated and presented a list of characters of the poem - the author in 1937 or the compilers of the volume - is difficult to determine.

Writing the heroes of the poem names since the second edition has undergone changes. If in the first edition of the poem in a book the names of the characters are printed exactly as in manuscript, in subsequent editions by the drafters amended in accordance with the established in the folklore tradition.

The most characteristic differences relate to punctuation marks. Compilers and/or editors of 1959 and 1992 editions put the punctuation according to modern rules of punctuation in Yakut language; removed some signs and replaced some signs with others. Authors "!!!” almost all replaced by "!”, signs "?!!” - on "!", "?!!” - on "?!", “..." - on ".". And also revealed a new division into sentences. Especially a lot of differences between with the manuscript and the first edition we can obtain in the edition of 1992. There are other discrepancies of spelling, and also some typos (especially in the edition of 1930). The causes of discrepancies are different: they arise either as a result of errors of the author, copyist, typesetter, proofreader, editor or as a result of changes in the text by the same persons (Likhachev, 2006, p.38). In our opinion, the author's signs should be restored, because they express the individual style of the writer. It is a mistake to remove the author's marks and/or replace them with other ones. But missing of the comma in the manuscript and the first edition must be put by the rules of modern punctuation, as it was done by the compilers of the publication in 1992.

Remark of 7th phenomena in the editions of 1959, 1992 is missing author's division of the paragraph, changed words order, and the author's note in parentheses ("*abáhy ôla"), which means "demon's son", is put to text of the remark. In the manuscript remarks continuation written with a new paragraph: "Aside from them stays one-eyed Demon's son in iron armor and flattened iron hat with one two-branched arm from the elbow and two-branched leg from the knee, armed with self-made firearm gun, aiming not where people are looking, but in the opposite direction. The warrior Aiyy comes to him and puts under his nose fig sign, so that he throws his head back» (I. 19).

In the edition of 1930, the author's note in parenthesis in text above was moved. This option should be restored in scientific text publication. On a given segment of text also highlighted some of differences, the 
causes of which are understandable ("angár"-"angar", "aiyy"-“Aiyy"). However, the word "tongonoguttan" we need to restore writing "tongologuttan" as it was written by the author and originally printed in previous editions. The Yakut word "tongolokh" (elbow) has another variant spelling of "toghonokh" (elbow) (Large explanatory dictionary of the Yakut language, 2013, pp.412, 452), not "tongonokh". In the latter case, it seems to us, admitted a typo. Unfortunately, in the 2005 edition, in the last printed edition of the text of the poem, is admitted the same typographical error (Oyunsky, 2005, p.227).

Should be noted another important difference in the text of the manuscript and the publication of 1930 compared with subsequent editions. In the first phenomenon of the first action P. A. Oyunsky divided song of boys and girls into separate stanzas and used the symbol "*" (manuscript L. 7). In the edition of 1930, the author's division into stanzas preserved and marked with the symbol “*” (Oyunsky, 1930, pp.14-15). In 1959 and 1992 editions the lyrics were published without division into stanzas.

Transferring of the sentence to another place identified in the 1992 publication, what affects contents of the work and refers to distortion of the text: a replica of the hero transferred to the words of people ("Jon sangata"). This error was corrected in the 2005 edition: the author's distribution of replicas was restored. Comparison of the manuscript text and printed sources clearly shows how the author's text has undergone changes. In the edition of 1992 the word "ümtü" changed to "ültü" (very strong) according to the modern spelling. However, in the text of other works of this publication, this word is printed in different ways: "üntü" ("not all are equal?!!"), "ültü" ("Iron horse"), "ümtü" (in translation of A. M. Gorky's poem "The Song of the Petrel").

There are many differences in spelling. In our view, the spelling of the writer should be restored according to the text of 1930 publication, which is important as the only lifetime edition and took into account the last creative will of the author.

\section{Conclusion}

Textological analysis of the work, its editions (if any exist), printed sources (lifetime and posthumous publications) often pursues publishing goals: the choice of the main text, the definition of publication type. Such analysis is also aimed at studying history of the text. Comparative analysis of manuscripts and lifetime editions of 1930 with the publications of 1959, 1992 of poem by P. A. Oyunsky "Tuyarima Kuo Fair-faced" revealed a significant difference in the punctuation of the author's text, the spelling, the cases of division into sentences, deleting paragraphs, moving sentences, etc. Verification of the manuscript and the lifetime edition of 1930 established that the text of this publication is the closest to the manuscript, it fully expresses the author's will: there are practically no discrepancies, preserved punctuation of the author. In this regard, this text can be adopted as the main text of the poem for further in-depth textual research, elimination of errors, inaccuracies and distortions made in subsequent publications, and also for establishment of the critical text of the work. The analysis of the manuscript made it possible to reveal new facts reflecting the creative work of the author on the text of the poem.

Thus, the results of this work allow to raise the question of the need for a special study in the aspect of textology and publishing practice of all texts of art works by P. A. Oyunsky in order to publish critically established texts, where the last will of the author would be reflected. 


\section{References}

Bilyukina, A. A. (1988). Yakut Soviet dramaturgy (origin and development of the social realism.) Moscow, Science.

Chervyachenko G. A. (1979). Soviet poem of 40-70-ies. Rostov-on-Don, Publishing house of Rostov University.

Danilov S. P. \& Okorokov G. G. (1978). Poetry of struggle and creation. Oyunsky P.A. Poems. Leningrad, Soviet writer, 5-33.

Grigorieva, L. P. (2004). From olonkho to dramatic poem. P. A. Oyunsky: myths and reality: collection of scientific articles /Acad. Sciences Rep. of Sakha (Yakutia), Institute of social research; Ex. ed. V. N. Ivanov. Yakutsk, 92-101.

Grigorieva, L. P. (2009). Compositional structure peculiarities of the dramatic poem of P.A. Oyunsky "Tuyarima Kuo Fair-faced". Maximova P. V., Grigorieva L. P. (2009). Compositional analysis of the poem (on the material of Yakut literature). Yakutsk, Yakutsk University publ., 87-99.

Grishunin A. L. (1998). Research aspects of textual criticism. Moscow: Heritage.

Large explanatory dictionary of the Yakut language in 15volumes (2013). (letter T) / ed. by P. A. Sleptsova. Novosibirsk, Science.

Likhachev D. S. (2006). Textology. Short essay. 2nd ed. Moscow.

National archives of Rep. S(Y). F. R57, op. 1, d. 671. L. 1-69.

Okorokova V. B. (2013). Oyunsky: (About life and work). Yakutsk, Sitim-Media

Oyunsky P. A. (1930). Tuyarima Kuo Fair-faced: Olonkho in 3 acts (from the national olonkho). Yakutsk. Yakut state book publishing house.

Oyunsky P. A. (1959). Works in 7 volumes. Plays Vol. 3. Yakutsk, Yakut state book publishing house.

Oyunsky P. A. (1968). Song of freedom / comp. S. P. Oyunskaya. Yakutsk, Yakut state book publishing house.

Oyunsky P. A. (1975). Selected works. In 2 volumes. Poems, translations, dramas. Vol.1. Yakutsk, Yakut state book publishing house.

Oyunsky P. A. (1978). Poems. Leningrad, Soviet writer.

Oyunsky P. A. (1992). Selected works. In 3 volumes. Poems, translations, dramatic poems. Vol.1. Yakutsk, National book publishing house of Sakha (Yakutia) Republic.

Oyunsky P. A. (2005). Collection of selected works / comp.: M. N. Sexton, S.P. Oyunskaya). Vol.1.: Poems, translations, dramatic poems. Yakutsk, Bichik.

Oyunsky P. A. (2015). Scientist, writer, statesman: materials of the regional scientific-practical conference with Russian and international participation, devoted to 120th anniversary of outstanding statesman and public figure, scientist, writer P.A. Sleptsov-Oyunsky birth, Yakutsk, 25-26 November 2013 / editorial board E. P. Antonov (ex. ed.) and others. Yakutsk, publishing house of the Institute of the Humanities and the Indigenous Peoples of the North of the Siberian Branch of the Russian Academy of Science. 
Platon Alekseevich Oyunsky. Life and work (2015): collection of archival documents / Archive Department of Sakha (Yakutia) Republic, National archive of Sakha (Yakutia) Republic; / comp.: N. S. Stepanova (resp. comp.) et al. Yakutsk, Bichik.

Reiser S. A. (1978). Fundamentals of textology. Ed. 2-th. Leningrad, Education.

Semenov V. A. Creativity of P.A. (1980). Oyunsky and the formation of socialist realism in the Yakut Soviet literature. Moscow, Science.

Sidorov O. G. (2016). Platon Oyunsky. Moscow, Young guard.

Sivtseva-Maksimova P. V. \& Nogovitsyn A. P. (2013). Basic texts of A.E. Kulakovsky: comparative analysis of discrepancies in publications of 1940-1970. Bulletin of the Bashkir University, 18(3), 841-844.

Tyurina E. (2009). About some of the publishing-textological problems of M. Bulgakov's novel "The heart of a Dog". Textual timeline. Russian literature of the XX century: questions of textology and source studies. Moscow, Institute of world literature. Russian Academy of Sciences, 101-116. 